\title{
TRAZENDO AS COISAS DE VOLIA À VIDA: EMARANHADOS CRIATIVOS NUM MUNDO DE MATERIAIS
}

\author{
Tim Ingold \\ University of Aberdeen - Escócia
}

Resumo: O artigo desenvolve os conceitos de antropologia ecológica criticando as noções de objeto e de rede e, por extensão a teoria do ator-rede. Desafiando a noção estabelecida de "objeto", propõe-se a retomada da noção de "coisa”, porosa e fluida, perpassada por fluxos vitais, integrada aos ciclos e dinâmicas da vida e do meio ambiente. A seguir, a teoria do ator-rede, de Latour, Law e Callon é criticada por manter e reproduzir uma divisão metafísica entre sujeitos e objetos (atribuindo a estes uma agência fetichizada) e ignorando a distribuição desigual de fluxos e sentidos ao longo da rede. Numa discussão inspirada em Heidegger e Deleuze, é proposta a ideia alternativa de "malha” (meshwork) para pensar a cultura material e as relações de comunicação, integração e fluxos entre coisas.

Palavras-chave: antropologia ecológica, cultura material, malha, teoria do ator-rede.

\begin{abstract}
The article broadens the concepts of Ecological Anthropology by criticizing the notions of object and network, and - by its extension - the Actor-Network Theory (ANT). Challenging the established notion of 'object', it proposes the return of the notion of 'thing', porous and fluid, permeated by vital flows, integrated into the dynamics of life and of the environment. Hereafter the Actor-Network Theory (of Latour, Callon and Law) is criticized for maintaining and reproducing a metaphysical division between subjects and objects (assigning to these a fetishized agency) and ignoring the unequal distribution of flows and directions along the network. In a discussion inspired by Heidegger and Deleuze, the article proposes an alternative idea of 'mesh' (meshwork) to think about the material culture and the communication relations, integration and flows among things.
\end{abstract}

Keywords: actor-network theory, ecological anthropology, material culture, meshwork. 
Em seus cadernos, o pintor Paul Klee defendia, e demonstrava através de exemplos, que os processos de gênese e crescimento que produzem as formas que encontramos no mundo em que habitamos são mais importantes que as próprias formas. "A forma é o fim, a morte”, escreveu ele; “o dar forma é movimento, ação. O dar forma é vida.” (Klee, 1973, p. 269). Essa ideia está no cerne do seu célebre "Credo criativo” de 1920: "A arte não reproduz o visível; ela torna visível” (Klee, 1961, p. 76). Em outras palavras, ela não busca replicar formas acabadas e já estabelecidas, seja enquanto imagens na mente ou objetos no mundo. Ela busca se unir às forças que trazem à tona a forma. Assim, como a planta cresce a partir de sua semente, a linha cresce a partir de um ponto que foi posto em movimento. Partindo de Klee, os filósofos Gilles Deleuze e Félix Guattari (2004, p. 377) argumentam que, em um mundo onde há vida, a relação essencial se dá não entre matéria e forma, substância e atributos, mas entre materiais e forças. Trata-se do modo como materiais de todos os tipos, com propriedades variadas e variáveis, são avivados pelas forças do cosmo, misturadas e fundidas umas às outras na geração de coisas. Na sua retórica, eles tentam superar a persistente influência de um modo de pensar as coisas e como elas são feitas e usadas que tem prevalecido no mundo ocidental durante os últimos dois milênios ou mais, ao menos desde Aristóteles.

Para criar algo, refletiu Aristóteles, deve-se juntar forma (morphé) e matéria (hyle). Na história subsequente do pensamento ocidental, esse modelo hilemórfico da criação arraigou-se ainda mais, mas também se desequilibrou. A forma passou a ser vista como imposta por um agente com um determinado fim ou objetivo em mente sobre uma matéria passiva e inerte. Quero argumentar aqui que os debates contemporâneos em campos os mais diversos - da antropologia e arqueologia à história da arte e estudos da cultura material continuam a reproduzir os pressupostos que subjazem ao modelo hilemórfico, ainda que tentem restaurar o equilíbrio entre seus termos. Meu objetivo final, por outro lado, é derrubar o próprio modelo, e substituí-lo por uma ontologia que dê primazia aos processos de formação ao invés do produto final, e aos fluxos e transformações dos materiais ao invés dos estados da matéria. Reembrando Klee, forma é morte; dar forma é vida. Em poucas palavras, meu objetivo é restaurar a vida num mundo que tem sido efetivamente morto nas palavras de teóricos para quem - nos termos de um de seus porta-vozes mais proeminentes - o caminho para a compreensão e para a empatia está "naquilo que as pessoas fazem com os objetos” (Miller 1998, p. 19).

Horizontes Antropológicos, Porto Alegre, ano 18, n. 37, p. 25-44, jan./jun. 2012 
Meu argumento tem cinco elementos, cada um dos quais corresponde a uma palavra-chave do meu título. Primeiramente, quero insistir que o mundo em que habitamos é composto não por objetos, mais por coisas. Devo estabelecer portanto uma distinção bem clara entre coisas e objetos. Em segundo lugar, definirei o que entendo por vida enquanto capacidade geradora do campo englobante de relações dentro do qual as formas surgem e são mantidas no lugar. Argumentarei que a atual ênfase da literatura na agência material é consequência de uma redução das coisas a objetos, e da sua correspondente "retirada” dos processos vitais. Com efeito, quanto mais os teóricos falam sobre agência, menos eles parecem ter a dizer sobre a vida; quero inverter essa ênfase. Em terceiro lugar, defenderei que esse foco nos processos vitais exige que abordemos não a materialidade enquanto tal, mas os fluxos de materiais. Como Deleuze e Guattari, temos que seguir esses fluxos, traçando os caminhos através dos quais a forma é gerada, onde quer que eles nos levem. Quarto, devo determinar o sentido específico no qual o movimento por esses caminhos é criativo; isso implica ler a criatividade "para frente" enquanto uma reunião improvisada com processos formativos, ao invés de "para trás” enquanto abdução, a partir de um objeto acabado, até uma intenção na mente do agente. Finalmente, eu mostrarei que os caminhos ou trajetórias através dos quais a prática improvisativa se desenrola não são conexões, nem descrevem relações entre uma coisa e outra. Eles são linhas ao longo das quais as coisas são continuamente formadas. Portanto, quando eu falo de um emaranhado de coisas, é num sentido preciso e literal: não uma rede de conexões, mas uma malha de linhas entrelaçadas de crescimento e movimento.

\section{Objetos e coisas}

Sentado no meu escritório enquanto escrevo, parece evidente que me encontro cercado de objetos de todo tipo: da cadeira e mesa que sustentam meu corpo e meu trabalho ao bloco de notas no qual escrevo, à caneta na minha mão e os óculos que se equilibram sobre meu nariz. Imaginemos por um instante que cada um desses objetos desaparecesse como por encanto, deixando apenas o chão, as paredes e o teto, vazios. Não posso fazer nada, a não ser ficar em pé ou andar sobre as tábuas do chão. Uma sala sem objetos, poderíamos concluir, é praticamente inabitável. Para que ela esteja pronta para qualquer atividade, 
ela deve ser mobiliada. Como sugerido pelo psicólogo James Gibson (1979) ao introduzir sua abordagem ecológica para a percepção visual, o mobiliário de um cômodo inclui as affordances ${ }^{1}$ que permitem ao morador realizar suas atividades quotidianas: a cadeira convida e permite sentar; a caneta, escrever; os óculos, enxergar; e por aí vai. De modo mais controverso, Gibson estendeu seu argumento do espaço interior de um cômodo para o ambiente de modo geral. Ele nos pede para imaginar um ambiente aberto, um "plano consistindo só na superfície da terra” (Gibson, 1979, p. 33). No caso-limite - ou seja, na ausência de qualquer objeto - um ambiente como esse seria percebido como um deserto perfeitamente plano, com um céu completamente limpo por cima e terra sólida por baixo, se estendendo em todas as direções até o grande círculo do horizonte. Que lugar desolado seria! Como as tábuas do chão da sala, a superfície da terra só nos permite ficar em pé e caminhar. Só podemos fazer mais que isso se o ambiente aberto, como o cômodo interno, estiver regularmente repleto de objetos. "Como os móveis num cômodo”, escreve Gibson (1979, p. 78), "a mobília da terra é o que a torna habitável”.

Deixemos agora o isolamento da sala para dar uma volta lá fora, ao ar livre. Nosso caminho nos leva a uma mata. Cercado de troncos e galhos, o ambiente decerto parece repleto. Mas ele está repleto de objetos? Suponhamos que nos concentremos numa árvore qualquer. Lá está ela, enraizada na terra, seu tronco se erguendo e seus galhos se abrindo, balançando ao vento, com ou sem brotos ou folhas, dependendo da estação. A árvore é um objeto? Em caso positivo, como a definiríamos? O que é árvore, e o que é não árvore? Onde termina a árvore e começa o resto do mundo? Essas não são questões fáceis de responder - ao menos não tão fáceis como parecem ser no caso dos móveis no meu escritório. A casca, por exemplo, é parte da árvore? Se eu retiro um pedaço e o observo mais de perto, constatarei que a casca é habitada por várias pequenas criaturas que se meteram por debaixo dela para lá fazerem suas casas. Elas são parte da árvore? E o musgo que cresce na superfície externa do tronco, ou os liquens que pendem dos galhos? Além disso, se decidimos que os insetos que vivem na casca pertencem à árvore tanto quanto a própria casca, então não há razão para excluirmos seus outros moradores, inclusive

1 Na literatura especializada, o termo - que designa a qualidade de um objeto que convida e permite se fazer algo com ele - tem sido mantido no inglês original (N. de T.).

Horizontes Antropológicos, Porto Alegre, ano 18, n. 37, p. 25-44, jan./jun. 2012 
o pássaro que lá constrói seu ninho ou o esquilo para o qual ela oferece um labirinto de escadas e trampolins. Se consideramos que o caráter dessa árvore também está em suas reações às correntes de vento no modo como seus galhos balançam e suas folhas farfalham, então poderíamos nos perguntar se a árvore não seria senão uma árvore-no-ar.

Essas considerações me levaram a concluir que a árvore não é um objeto, mas um certo agregado de fios vitais. É isso que entendo por coisa. Aqui, sigo de modo frouxo o argumento clássico avançado pelo filósofo Martin Heidegger. Em seu célebre ensaio sobre A coisa, Heidegger (1971) buscou delinear justamente o que diferiria uma coisa de um objeto. O objeto coloca-se diante de nós como um fato consumado, oferecendo para nossa inspeção suas superfícies externas e congeladas. Ele é definido por sua própria contrastividade com relação à situação na qual ele se encontra (Heidegger 1971, p. 167). A coisa, por sua vez, é um “acontecer”, ou melhor, um lugar onde vários aconteceres se entrelaçam. Observar uma coisa não é ser trancado do lado de fora, mas ser convidado para a reunião. Nós participamos, colocou Heidegger enigmaticamente, na coisificação da coisa em um mundo que mundifica. Há decerto um precedente dessa visão da coisa como uma reunião no significado antigo da palavra: um lugar onde as pessoas se reúnem para resolver suas questões. Se pensamos cada participante como seguindo um modo de vida particular, tecendo um fio através do mundo, então talvez possamos definir a coisa, como eu já havia sugerido, como um "parlamento de fios” (Ingold, 2007b, p. 5). Assim concebida, a coisa tem o caráter não de uma entidade fechada para o exterior, que se situa no e contra o mundo, mas de um nó cujos fios constituintes, longe de estarem nele contidos, deixam rastros e são capturados por outros fios noutros nós. Numa palavra, as coisas vazam, sempre transbordando das superfícies que se formam temporariamente em torno delas.

Voltarei a esse ponto quando falar da importância de seguir os fluxos de materiais. Por ora, permita-me retomar nosso passeio ao ar livre. Nós observávamos a árvore; o que mais poderia chamar nossa atenção? Tropeço numa pedra no meio do caminho. Com certeza, você talvez diria, a pedra é um objeto. Mas ela só o é se nós a extrairmos do processo de erosão e deposição que a levou até aquele lugar, e lhe conferiu seu presente tamanho e forma. Uma pedra que rola, diz o provérbio, não junta musgo. Mas no próprio processo de juntar musgo, a pedra em repouso torna-se uma coisa; por outro lado, a pedra que rola - como um seixo na correnteza de um rio - torna-se uma coisa no

Horizontes Antropológicos, Porto Alegre, ano 18, n. 37, p. 25-44, jan./jun. 2012 
ato mesmo de rolar. Assim como a árvore que responde através de seus movimentos às correntes de vento é uma árvore-no-ar, a pedra que rola levada pela corrente do rio é uma pedra-na-água. Suponhamos agora que lancemos nosso olhar para cima. É um dia bonito, mas há algumas nuvens no céu. As nuvens são objetos? Curiosamente, Gibson pensa que sim: para ele, elas parecem estar dependuradas no céu, enquanto outras entidades como árvores e pedras repousam sobre a terra. O ambiente como um todo, nas palavras de Gibson (1979, p. 66), “consiste na terra e no céu com objetos na terra e no céu”. O pintor René Magritte fez uma paródia engenhosa dessa concepção de céu mobiliado ao representar a nuvem como um objeto voador flutuando através da porta aberta de um cômodo vazio. É claro que a nuvem não é realmente um objeto, mas uma intumescência de vapores que se incha à medida em que é carregada por correntes de ar. Observar as nuvens, eu diria, "não é ver a mobília do céu, mas vislumbrar o céu-em-formação, nunca o mesmo entre um momento e outro” (Ingold, 2007a, p. S28). Novamente, nuvens não são objetos, e sim coisas.

O que vale para coisas como árvores, pedras e nuvens, que normalmente crescem e se formam com pouca ou nenhuma intervenção humana, também se aplica a estruturas mais ostensivamente artificiais. Consideremos um prédio: não a estrutura fixa e final do projeto do arquiteto mas o prédio real, repousando sobre suas fundações dentro da terra, fustigado pelo clima, e suscetível de receber visitas de pássaros, roedores e fungos. O notável arquiteto português Alvaro Siza (1997, p. 47) admitiu que nunca foi capaz de produzir uma casa real, ou seja, "uma máquina complicada na qual todo dia algo estraga”. A casa real nunca fica pronta. Ela exige de seus moradores um esforço contínuo de reforço face ao vaivém de seus habitantes humanos e não humanos, para não falar do clima! A água das chuvas pinga através do telhado onde o vento carregou uma telha, alimentando o crescimento de fungos que ameaçam decompor a madeira. As canaletas estão cheias de folhas apodrecidas, e, como se não bastasse, lamenta Siza (1997, p. 48), "legiões de formigas invadem o batente das portas, e há sempre cadáveres de pássaros, ratos e gatos”. Não muito diferente da árvore. A casa real é uma reunião de vidas, e habitá-la é se juntar à reunião - ou, nos termos de Heidegger (1971), participar com a coisa na sua coisificação. Como explica Juhani Pallasmaa (1996), nossas experiências arquitetônicas mais fundamentais são verbais e não nominais. Elas consistem não em encontros com objetos - a fachada, a padieira da porta, a janela e a lareira - mas em atos de se aproximar e entrar, olhar para dentro ou para fora,

Horizontes Antropológicos, Porto Alegre, ano 18, n. 37, p. 25-44, jan./jun. 2012 
absorver o calor da lareira (Pallasmaa 1996, p. 45). Enquanto moradores, nós experimentamos a casa não como objeto, mas como coisa.

\section{Vida e agência}

O que nós aprendemos ao escancarar as janelas do escritório, sair de casa e dar um passeio lá fora? Encontramos um ambiente entulhado de objetos como no meu escritório cheio de móveis, livros e utensílios? Longe disso; parece não haver objeto algum. Decerto há inchaços, crescimentos, afloramentos, filamentos, rupturas e cavidades, mas não objetos. Embora nós possamos ocupar um mundo repleto de objetos, para o ocupante os conteúdos do mundo parecem já se encontrar trancados em suas formas finais, fechados em si mesmos. É como se eles tivessem nos dado as costas. Habitar o mundo, ao contrário, é se juntar ao processo de formação. E o mundo que se abre aos habitantes é fundamentalmente um ambiente sem objetos - numa palavra, ASO. Lembremos que, para Gibson, um ambiente sem objetos seria um deserto nu e perfeitamente plano. Em seus termos, somente quando se acrescenta objetos - colocados sobre o chão ou pendurados no céu - um ambiente torna-se habitável. Como chegamos então a uma conclusão oposta, ou seja, que um ambiente repleto de objetos pode ser ocupado mas não habitado? O que marca a diferença entre a visão de Gibson e a nossa? A resposta está nas nossas diferentes concepções sobre a significância das superfícies.

Segundo Gibson, é através de suas superfícies externas que os objetos são revelados à percepção. Cada superfície, explica ele, é uma interface entre a substância mais ou menos sólida de um objeto e o meio volátil que o circunda. Se a substância é dissolvida ou evapora no meio, a superfície desaparece e com ela o objeto que ela envolvia (Gibson, 1979, p. 16, 106). Assim, a própria qualidade de objeto de qualquer entidade está na separação e imiscibilidade entre substância e meio. Porém, remova-se qualquer objeto, e ainda fica uma superfície - para Gibson, a superfície mais fundamental de todas, o chão, que marca a interface entre a substância da terra embaixo e o meio gasoso do céu em cima. A terra deu as costas para o céu, então? Se fosse assim, como supôs corretamente Gibson, a vida não seria possível. O ambiente aberto não poderia ser habitado. Nosso argumento, por outro lado, é que o mundo aberto pode ser habitado justamente porque, onde quer que haja vida, a separação da interface 
entre terra e céu dá lugar à mútua permeabilidade e conectividade. O que chamamos vagamente de chão não é uma superfície coerente, mas uma zona na qual o ar e a umidade do céu se combinam com substâncias cuja fonte está na terra, na formação contínua das coisas vivas. Sobre uma semente que cai no chão, Paul Klee (1973, p. 29) escreve que "a relação com a terra e a atmosfera dá-lhe a capacidade de crescer [...] A semente cria raízes. Inicialmente, a linha se dirige para a terra; não para morar lá, mas para retirar a energia que precisa para alçar o ar.” Durante o crescimento, o ponto se torna uma linha, mas a linha, longe de ser seguir a superfície pré-preparada do chão, contribui para seu trançado mutante.

Em suma, não pode haver vida num mundo onde o céu e a terra não se misturam. Para termos uma ideia do que significa habitar esse mundo terra-céu podemos voltar a Heidegger. Numa passagem reconhecidamente floreada, ele descreve a terra como "o detentor servente, florido e frutífero, dispersando-se em rocha e água, erguendo-se em planta e animal”. E do céu ele escreve que é "o caminho abobadado do sol, o curso das mudanças lunares, o brilho itinerante das estrelas, as estações sazonais e suas mudanças, a luz e o crepúsculo do dia, a escuridão e o brilho da noite, a bonança e a não bonança do clima, as nuvens flutuantes e o azul profundo do éter”. Além disso, não se pode falar da terra sem pensar no céu, e vice-versa. Um partilha da essência do outro (Heidegger 1971, p. 149). Como é diferente da descrição feita por Gibson (1979, p. 66) da terra e céu como domínios mutuamente excludentes, rigidamente separados pela superfície do chão e habitados por seus respectivos objetos: "montanhas e nuvens, fogo e pôr do sol, seixos e estrelas”! No lugar dos substantivos de Gibson que denotam itens de mobiliário, a descrição de Heidegger se vale de verbos de crescimento e movimento. No "erguer-se” da terra, coloca ele, na descarga irreprimível de substância através das superfícies porosas de formas emergentes, encontramos a essência da vida. As coisas estão vivas, como já notei, porque elas vazam. A vida no ASO não é contida; ela é inerente às próprias circulações de materiais que continuamente dão origem à forma das coisas ainda que elas anunciem sua dissolução.

É através de sua imersão nessas circulações, portanto, que as coisas são trazidas à vida. Isso pode ser demonstrado através de um experimento simples que realizei com meus alunos na Universidade de Aberdeen. Utilizando um quadrado de papel, vareta de bambu, fita, durex, cola e corda, é fácil fazer uma pipa. Fizemo-la num ambiente fechado, trabalhando sobre mesas. Para

Horizontes Antropológicos, Porto Alegre, ano 18, n. 37, p. 25-44, jan./jun. 2012 
todos os propósitos, parecia que estávamos montando um objeto. Mas quando levamos nossas criações para fora, tudo mudou. Elas de repente passaram à ação, rodopiando, girando, mergulhando de cabeça, e - apenas ocasionalmente - voando. O que aconteceu? Alguma força vital adentrou nas pipas como mágica, fazendo-as agir de modo alheio à nossa vontade? É claro que não. As pipas estavam agora imersas em correntes de vento. A pipa que repousava sem vida sobre a mesa dentro da sala tinha se transformado numa pipa-no-ar. Não era mais um objeto - se é que jamais o foi - mas uma coisa. Assim como a coisa existe na sua coisificação, a pipa-no-ar existe no seu voo. Colocando de outro modo, a partir do momento em que foi levada para fora, a pipa deixou de figurar em nossa percepção como um objeto que pode ser colocado em movimento para tornar-se um movimento que se resolve na forma de uma coisa. Poder-se-ia dizer o mesmo de um pássaro-no-ar, ou de um peixe-na-água. O pássaro é o seu voar; o peixe, o seu nadar. O pássaro pode voar graças às correntes e vórtices que ele introduz no ar, e o peixe pode nadar velozmente devido aos turbilhonamentos que ele causa com o movimento de suas nadadeiras e cauda. Cortados dessas correntes, eles estariam mortos.

É aqui que chegamos - e, espero, enterremos para sempre - o chamado "problema da agência” (Gell, 1998, p. 16). Muito já foi escrito sobre as relações entre pessoas e objetos com base na ideia de que a diferença entre eles é longe de ser absoluta. Se as pessoas podem agir sobre os objetos que as circundam, então, argumenta-se, os objetos "agem de volta” e fazem com que elas façam, ou permitem que elas alcancem, aquilo que elas de outro modo não conseguiriam (ver, por exemplo, Gosden, 2005; Henare; Holbraad; Wastell, 2007; Knappett, 2005; Latour, 2005; Malafouris; Knappett, 2008; Miller, 2005; Tilley, 2004). Não obstante, no primeiro movimento teórico que toma as coisas para enfocá-las em sua qualidade de objeto (objectness), elas são retiradas dos fluxos que as trazem à vida. Vimos isso com a pipa. Pensar a pipa como um objeto é omitir o vento - esquecer que ela é, antes de tudo, uma pipa-no-ar. E, assim parece, o voo da pipa é resultado da interação entre uma pessoa (quem a empina) e um objeto (a pipa); enquanto tal, ele só pode ser explicado imaginando que a pipa seja dotada de um princípio animador interno, uma agência, que a coloca em movimento, na maioria das vezes contraria a vontade daquele que a empina. De modo mais geral, sugiro que o problema da agência nasce da tentativa de reanimar um mundo de coisas já morto ou tornado inerte pela interrupção dos fluxos de substância que lhe dão vida. No ASO, 
as coisas se movem e crescem porque elas estão vivas, não porque elas têm agência. E elas estão vivas precisamente porque não foram reduzidas ao estado de objeto. A ideia de que objetos têm agência é, na melhor das hipóteses, uma figura de linguagem, imposta a nós (anglófonos, ao menos) pela estrutura de uma linguagem que exige de todo verbo de ação um sujeito nominal. Na pior, ela tem levado grandes mentes a se enganar de um modo que não gostaríamos de repetir. Com efeito, tomar a vida de coisas pela agência de objetos é realizar uma dupla redução: de coisas a objetos, e de vida a agência. A fonte dessa lógica redutivista é, acredito, o modelo hilemórfico.

\section{Materiais e materialidade}

Quando os analistas falam do “mundo material”, ou mais abstratamente de “materialidade”, o que eles querem dizer (Ingold, 2007c)? Que sentido faz invocar a materialidade de pedras, árvores, nuvens, prédios ou mesmo pipas? Coloque essa questão para estudiosos da cultura material e provavelmente terá respostas contraditórias. Assim uma pedra, segundo Christopher Tilley (2007), pode ser vista em sua “materialidade bruta”, simplesmente como um agregado amorfo de matéria. Não obstante, pensa ele, precisamos de um conceito de materialidade para compreender como determinados pedaços de pedra adquirem forma e significado dentro de contextos sociais e históricos particulares (Tilley, 2007, p. 17). No mesmo sentido, o arqueólogo Joshua Pollard (2004, p. 48) explica que “por materialidade entendo como o caráter material do mundo é compreendido, apropriado e envolvido em projetos humanos”. Podemos reconhecer em ambos os enunciados os dois lados do modelo hilemórfico: de um lado, a materialidade bruta ou o "caráter material” do mundo; de outro, a agência dos seres humanos que lhe dá forma. No conceito de materialidade, a divisão entre matéria e forma é reproduzida ao invés de colocada em questão. O próprio conceito de cultura material é uma expressão contemporânea do hilemorfismo matéria-forma. Quando Tilley escreve sobre “materialidade bruta” ou o arqueólogo Bjørnar Olsen (2003, p. 88) fala da “fisicalidade dura do mundo”, é como se o mundo tivesse interrompido sua mundificação e cristalizado na forma de um precipitado sólido e homogêneo, à espera de ser diferenciado pela sobreposição de uma forma cultural. Nesse mundo estável e estabilizado, nada flui. Não pode haver vento, clima, nem 
chuva para umidificar a terra ou os rios que correm por ela, muito menos o “erguer-se” da terra enquanto planta ou animal - não pode haver vida. Não pode haver coisas, somente objetos.

Em suas tentativas de reequilibrar o modelo hilemórfico, os teóricos têm insistido que o mundo material não é passivamente subserviente aos desígnios humanos. Não obstante, tendo interrompido o fluxo de materiais eles só são capazes de compreender a atividade que ocorre do lado do mundo material atribuindo agência a objetos. Pollard, contudo, diverge um pouco. Ao concluir um importante artigo sobre "a arte da deterioração e a transformação da substância”, ele nota que coisas materiais, assim como pessoas, são processos, e que sua agência real está justamente no fato de que "elas nem sempre podem ser capturadas e contidas” (Pollard, 2004, p. 60). Como vimos, é no contrário da captura e da contenção - na descarga e vazamento - que descobrimos a vida das coisas. Com isso em mente, podemos voltar a Deleuze e Guattari (2004, p. 451, grifo dos autores), que insistem que onde quer que encontremos matéria, esta é "matéria em movimento, em fluxo, em variação"; e a consequência, continuam eles, é que "essa matéria-fluxo só pode ser seguida”. O que Deleuze e Guattari chamam aqui de "matéria-fluxo", eu chamaria de material. No mesmo sentido, retomo essa asserção na forma de uma regra simples: seguir os materiais. Quero sugerir que o ASO não é um mundo material mas um mundo de materiais, de matéria em fluxo. Seguir esses materiais é entrar num mundo, por assim dizer, em fervura constante. No lugar de compará-lo a um grande museu ou loja de departamentos nos quais os objetos encontram-se dispostos de acordo com seus atributos ou origem, seria melhor imaginar o mundo como uma grande cozinha, bem abastecida com ingredientes de todo tipo.

Na cozinha, as coisas são misturadas em combinações variadas, gerando nesse processo novos materiais que serão por sua vez misturados a outros ingredientes num processo de transformação sem fim. Para cozinhar, devemos abrir recipientes e retirar seus conteúdos. Temos que destampar coisas. Em face das proclividades anárquicas de seus materiais, o cozinheiro ou cozinheira tem que se esforçar para manter alguma aparência de controle sobre o que se passa. Um paralelo talvez ainda mais próximo seja com o laboratório do alquimista. Segundo a alquimia, explica o historiador da arte James Elkins (2000), a matéria no mundo não podia ser descrita segundo os princípios da ciência, em termos de sua composição atômica ou molecular; tratava-se substâncias conhecidas pelo modo como eram vistas e sentidas, e pelo que se 
passava com elas ao serem misturadas, aquecidas e resfriadas. Os óleos, por exemplo, não eram hidrocarbonetos, mas "aquilo que subia à superfície de uma panela com plantas em cozimento, ou o que se assentava, negro e fétido, no fundo de um fosso com carne de cavalo apodrecida” (Elkins, 2000, p. 19). A alquimia, escreve Elkins (2000, p. 23), “é a antiga ciência de lidar com os materiais, e não entender muito bem o que se passa com eles”. Seu argumento é que os pintores sempre fizeram algo parecido em seu trabalho quotidiano. Seu conhecimento também incluía substâncias, e estas não eram no geral muito diferentes daquelas encontradas no laboratório do alquimista. A cola do pintor, por exemplo, era feita de casco de cavalo, chifre de veado e pele de coelho, e a tinta era misturada com cera de abelha, leite de figo e resinas de plantas tóxicas. Os pigmentos eram obtidos a partir de uma miscelânea bizarra de ingredientes, como pequenos insetos avermelhados que eram fervidos e secos ao sol para produzir o vermelho profundo conhecido como carmim, ou vinagre e esterco de cavalo que eram misturados com chumbo em potes de cerâmica para produzir a melhor tinta branca.

Como os praticantes no ASO, o que o cozinheiro, o alquimista e o pintor fazem não é impor forma à matéria, mas reunir materiais diversos e combinar e redirecionar seu fluxo tentando antecipar aquilo que irá emergir. O mesmo pode ser dito do ceramista, como sugerido pelo arqueólogo Benjamin Alberti (2007) num excelente estudo sobre cerâmicas datando do primeiro milênio d.C. encontradas no noroeste da Argentina. Seria um erro, argumenta ele, presumir que a cerâmica é um objeto fixo e estável, que traz a marca da forma cultural sobre a matéria “dura” do mundo físico (Alberti 2007, p. 211). Pelo contrário, as evidências sugerem que os potes eram tratados como corpos, e com a mesma preocupação: compensar pela estabilidade crônica, reforçar os recipientes contra a constante suscetibilidade a vazamento e descarga que ameaça lhes dissolver ou metamorfosear. Como parte da fábrica do ASO, as cerâmicas não são mais estáveis que corpos; são constituídas e mantidas no lugar dentro de fluxos de materiais. Deixados ao léu, os materiais fogem do controle. Potes se quebram, corpos desintegram. Esforço e vigilância são necessários para manter as coisas intactas, sejam elas potes ou pessoas. O mesmo vale para o jardineiro, que deve estar sempre vigilante para impedir que o jardim se transforme numa mata.

A sociedade moderna, é claro, tem aversão ao caos. Mas por mais que ela tenha tentado, através da engenharia, construir um mundo material à altura 
das suas expectativas - ou seja, um mundo de objetos discretos e bem ordenados -, suas aspirações são constantemente frustradas pela recusa da vida em ser contida. Podemos pensar que objetos têm superfícies externas, mas onde quer que haja superfícies a vida depende da troca contínua de materiais através delas. Se, ao transformar a terra em superfície ou encarcerar corpos, nós bloqueamos essas trocas, nada poderá viver. Na prática, esses bloqueios só podem ser parciais e provisórios. A superfície dura da terra, por exemplo, talvez seja a característica mais saliente do que chamamos convencionalmente de “ambiente construído”. Numa estrada asfaltada ou fundação de concreto, nada pode crescer, a menos que haja um abastecimento a partir de fontes remotas. Mas mesmo o mais resistente dos materiais não pode resistir para sempre aos efeitos da erosão e desgaste. A superfície asfaltada, atacada por raízes por baixo e pela ação do vento, chuva e geadas por cima, eventualmente racha e se espedaça, permitindo às plantas crescerem através dela para se misturarem e se ligarem novamente à luz, ao ar e à umidade da atmosfera. Onde quer que olhemos, os materiais ativos da vida estão vencendo a mão morta da materialidade que tenta tolhê-los.

\section{Improvisação e abdução}

Ao trazer as coisas à vida, eu quis celebrar a criatividade daquilo que Klee chamou de “dar forma”. É importante, contudo, ser mais preciso a respeito do que entendo por criatividade. Especificamente, tenho interesse em reverter uma tendência, evidente em grande parte da literatura sobre arte e cultura material, de ler a criatividade "de trás para frente”: começando pelo resultado na forma de um objeto novo e traçando-a, através de uma sequência de condições prévias, a uma ideia sem precedentes na mente de um agente. Essa leitura de trás para frente equivale ao que o antropólogo Alfred Gell chamou de abdução da agência. Todo trabalho de arte, para Gell (1998, p. 13), é um "objeto" que pode ser "relacionado a um agente social de uma maneira distintiva, do 'tipo arte””. Por “do tipo arte”, Gell entende uma situação na qual é possível traçar uma cadeia de conexões causais que vai do objeto até o agente, através da qual este último pode ser pensando como indexando o primeiro. Traçar essas conexões é realizar a operação cognitiva da abdução. Diante da minha crítica anterior à dupla redução de coisas a objetos, e de vida a agência, 
deve estar claro que acredito que essa visão seja equivocada. Um trabalho de arte, insisto, não é um objeto mas uma coisa - e, como argumentou Klee, o papel do artista não é reproduzir uma ideia preconcebida, nova ou não, mas juntar-se a e seguir as forças e fluxos dos materiais que dão forma ao trabalho. "Seguir", como colocam Deleuze e Guattari (2004, p. 410), “não é o mesmo que reproduzir”: enquanto reproduzir envolve um procedimento de interação, seguir envolve itineração. O (ou a) artista - assim como o artesão - é um itinerante, e seu trabalho comunga com a trajetória de sua vida. Além disso, a criatividade do seu trabalho está no movimento para frente, que traz à tona as coisas. Ler as coisas "para frente” implica um enfoque não na abdução, mas na improvisação (Ingold; Hallam 2007, p. 3).

Improvisar é seguir os modos do mundo à medida que eles se desenrolam, e não conectar, em retrospecto, uma série de pontos já percorridos. É, como escrevem Deleuze e Guattari (2004, p. 344), “juntar-se ao Mundo, misturar-se a ele. Nos aventuramos para fora de casa através da linha de uma melodia”. A vida, para Deleuze e Guattari, se desenrola ao longo dessas linhas-fios; eles a chamam de "linha de fuga", e por vezes "linhas de devir". O mais importante, contudo, é que essas linhas não conectam. "Uma linha de devir”, escrevem eles, "não é definida pelos pontos que ela conecta, nem pelos pontos que a compõem. Pelo contrário, ela passa entre pontos, insurge no meio deles [...] Um devir não é nem um nem dois, nem a relação entre os dois; é o entre, a [...] linha de fuga [...] que corre perpendicular a ambos.” (Deleuze; Guattari, 2004, p. 323). Assim, na vida, como na música ou na pintura, no movimento do devir - o crescimento da planta a partir da semente, o soar da melodia a partir do encontro do violino com o arco, o movimento do pincel e seu traço - os pontos não são conectados, mas colocados de lado e tornados indiscerníveis pela corrente à medida que ela se arrasta através deles. A vida está sempre em aberto: seu impulso não é alcançar um fim, mas continuar seguindo em frente. A planta, o músico ou o pintor, ao seguirem em frente, “arriscam uma improvisação” (Deleuze; Guattari, 2004, p. 343).

A coisa, todavia, não é só um fio, mas um certo agregar de fios da vida. Deleuze e Guattari (2004, p. 290) a chamam de ecceidade. Mas se tudo é um feixe de linhas, o que fazer do nosso conceito original de "ambiente”? Qual o significado de ambiente no ASO? Literalmente, um ambiente é aquilo que cerca alguma coisa, mas não se pode cercar nada sem envolvê-lo, convertendo os fios ao longo dos quais a vida é vivida em limites dentro dos quais ela é 
contida. Ao invés disso, vamos nos imaginar, como fez Charles Darwin (1950, p. 64) em A origem das espécies, em face de "plantas e moitas revestindo uma margem emaranhada". Observe como os feixes fibrosos que constituem cada planta e moita se entrelaçam para formar um denso tapete de vegetação. O que costumamos chamar de "ambiente" reaparece na margem como um imenso emaranhado de linhas. Essa concepção foi avançada pelo geógrafo sueco Torsten Hägerstrand (1976), que imaginou cada elemento constituinte do ambiente - humanos, animais, plantas, pedras, prédios - como tendo uma trajetória contínua de devir. À medida em que eles se movem através do tempo e se encontram, as trajetórias desses diversos elementos são enfeixadas em combinações diversas. "Vistos de dentro", escreveu Hägerstrand (1976, p. 332), "pode-se pensar as pontas das trajetórias como sendo às vezes empurradas para frente por forças que vêm de trás, às vezes olhando em volta e estendendo os braços, a cada momento perguntando ‘o que eu faço agora'?”; nos termos de Hägerstrand, o emaranhar dessas trajetórias que não param de se estender constitui a textura do mundo - "a grande tapeçaria da Natureza tecida pela história”. Como a margem emaranhada de Darwin, a tapeçaria de Hägerstrand é um campo não de pontos interconectados mas de linhas entrelaçadas; não uma rede (network), mas o que eu gostaria de chamar de malha (meshwork).

\section{Rede e malha}

Tomei o termo "malha” de empréstimo da filosofia de Henri Lefebvre. Há algo em comum, Lefebvre (1991) nota, entre o modo como as palavras são inscritas numa página de texto e o modo como os movimentos e ritmos da atividade humana e não humana são registrados no espaço vivido. Mas isso apenas se pensarmos a escrita não como uma composição verbal, mas como uma malha de linhas - não como texto, mas como textura. “A atividade prática escreve na natureza”, nota ele, “com uma mão que rabisca” (Lefebvre, 1991, p. 117). Pense nas trilhas reticulares deixadas por pessoas e animais à medida que eles seguem sua vida na casa, vila e cidade. Capturado nesses múltiplos emaranhados, cada monumento ou prédio é mais "arqui-textural” que arquitetônico. Apesar de sua aparente permanência e solidez, eles também têm uma ecceidade que é sucessivamente experimentada nos panoramas, oclusões e 
transições que se desenrolam ao longo da miríade de caminhos tomados pelos habitantes, de um cômodo a outro, saindo e entrando de portas, no ritmo dos seus afazeres quotidianos. Voltamos aqui à observação de Pallasmaa de que nossa experiência arquitetônica é mais verbal que nominal. À medida que a vida dos habitantes vai transbordando para jardins e ruas, campos e matas, o mundo vaza para dentro do prédio, produzindo ecos de reverberação e padrões de luz e sombra característicos. É nesses fluxos e contrafluxos, serpenteando através ou entre, sem começo nem fim - e não enquanto entidades conectadas com limites interiores ou exteriores - que as coisas são evidenciadas no mundo do ASO.

Essa distinção entre as linhas de fluxo da malha e as linhas de conexão da rede é crucial. Não obstante, ela tem sido persistentemente obscurecida, sobretudo na elaboração mais recente do que tem sido chamado, um tanto desafortunadamente, de "teoria do ator-rede”. Essa teoria tem suas raízes não numa reflexão sobre o ambiente, mas no estudo sociológico da ciência e tecnologia. Parte importante do seu apelo neste último campo vem da sua promessa de descrever interações entre pessoas (como cientistas e engenheiros) e os objetos com os quais elas lidam (como no laboratório) de uma maneira que não concentre a agência em mãos humanas, mas a entenda como distribuída por todos os elementos que se encontram conectados ou mutuamente implicados num campo de ação. O termo "ator-rede" (actor-network) chegou à literatura anglófona como tradução do francês acteur réseau. E como um de seus principais proponentes, Bruno Latour, observou em retrospecto, essa tradução lhe emprestou um significado que não era pretendido. No uso comum, que inclui inflexões relativas a inovações no campo das tecnologias de informação e comunicação, o atributo definidor da rede é sua conectividade (Latour, 1999, p. 15). Mas réseau pode se referir tanto a rede (network) como a tecer (netting) - tecer uma malha, o bordado de uma renda, o plexo do sistema nervoso, ou a teia de uma aranha.

Diferente das redes de comunicação, por exemplo, os fios de uma teia de aranha não conectam pontos ou ligam coisas. Eles são tecidos a partir de materiais exsudados pelo corpo da aranha, e são dispostos segundo seus movimentos. Nesse sentido, eles são extensões do próprio ser da aranha à medida que ela vai trilhando o ambiente (Ingold, 2008, p. 210-211). Eles são as linhas ao logo das quais a aranha vive, e conduzem sua percepção e ação no mundo. O acteur réseau foi originalmente concebido por seus criadores (se não por 
aqueles que foram confundidos por sua tradução enquanto "rede") para indicar justamente essas linhas de devir. Sua inspiração veio, em larga medida, da filosofia de Deleuze e Guattari. E esses autores são explícitos ao afirmar que, embora o valor da teia para a aranha esteja no fato de ela capturar moscas, o fio da teia não liga a aranha à mosca, assim como a "linha de fuga" da mosca tampouco a liga à aranha. Essas duas linhas se desenrolam em contraponto: uma serve de refrão à outra. Esperando no centro de sua teia, a aranha registra que uma mosca aterrissou em algum lugar nas margens externas quando ela envia vibrações através dos fios que são captadas por suas pernas finas e supersensíveis. Ela pode então correr através dos fios da teia para reivindicar sua presa. Assim, as linhas-fios da teia colocam as condições de possibilidade para que a aranha interaja com a mosca. Mas elas não são, em si, linhas de interação. Se essas linhas são relações, então elas são relações não entre, mas ao longo de.

É claro, assim como a aranha, as vidas das coisas geralmente se estendem ao longo não de uma mas de múltiplas linhas, enredadas no centro mas deixando para trás inúmeras "pontas soltas” nas periferias. Assim, cada coisa pode ser vislumbrada, como Latour (2005, p. 177) tem sugerido mais recentemente, no formato de uma estrela "com um centro cercado de muitas linhas que irradiam, com uma multiplicidade de condutores mínimos transmitindo de um lado para o outro". Não mais um objeto autocontido, a coisa aparece agora como uma teia ramificante de linhas de crescimento. Eis a ecceidade de Deleuze e Guattari (2004, p. 290), celebremente associada por eles a um rizoma. Pessoalmente, eu prefiro a imagem de um micélio (Rayner, 1997). Qualquer que seja a imagem escolhida, o crucial é que comecemos pelo caráter fluido do processo vital, onde os limites são sustentados graças ao fluxo de materiais através deles. Na ciência da mente, o caráter absoluto da fronteira entre corpo e ambiente tem sido há muito objeto de críticas. Mais de 50 anos atrás, o pioneiro da antropologia psicológica A. Irving Hallowell (1955, p. 88) sugeriu que "qualquer dicotomia interno-externo que tenha a pele humana como limite é psicologicamente irrelevante”. Essa visão viria a ser ecoada pelo antropólogo Gregory Bateson (1973, p. 429) numa palestra proferida em 1970, na qual ele declarou que "o mundo mental - a mente, o mundo do processamento da informação - não é delimitado pela pele”. Bem mais recentemente, o filósofo Andy Clark fez o mesmo ponto. A mente, nos diz Clark (1997, p. 53), é um “órgão vazado”, que não pode ser confinado dentro 
do crânio, que se mistura com o corpo e com o mundo durante a execução de suas operações. Mais precisamente, ele deveria ter dito que o crânio é vazado, e que é a mente que vaza através dele! Seja como for, o que busquei aqui foi voltar à declaração de Bateson e levá-la um passo à frente. Quero sugerir que não é apenas a mente que vaza, mas as coisas de modo geral. E elas o fazem ao longo dos caminhos que seguimos à medida que traçamos os fluxos de materiais do ASO.

Traduzido do inglês por Leticia Cesarino.

\section{Referências}

ALBERTI, B. Destabilising meaning in anthropomorphic forms of northwest Argentina. In: JORGE, V. O.; THOMAS, J. (Ed.). Overcoming the modern invention of material culture. Porto: ADECAP, 2007. p. 209-223. Edição especial do Journal of Iberian Archaeology 9/10.

BATESON, G. Steps to an ecology of mind. London: Granada, 1973.

CLARK, A. Being there. Cambridge, MA: MIT Press, 1997.

DARWIN, C. On the origin of species by means of natural selection. London: Watts, 1950. Reimpressão da primeira edição de 1859.

DELEUZE, G.; GUATTARI, F. A thousand plateaus. Trans. B. Massumi. London: Continuum, 2004.

ELKINS, J. What painting is. London: Routledge, 2000.

GELL, A. Art and agency. Oxford: Clarendon, 1998.

GIBSON, J. J. The ecological approach to visual perception. Boston: Houghton Mifflin, 1979.

GOSDEN, C. What do objects want? Journal of Archaeological Method and Theory, v. 12, n. 3, p. 193-211, 2005. 
HÄGERSTRAND, T. Geography and the study of the interaction between nature and society. Geoforum, v. 7, n. 5-6, p. 329-334, 1976.

HALLOWELL, A. I. Culture and experience. Philadelphia: University of Pennsylvania Press, 1955.

HEIDEGGER, M. Poetry, language, thought. Trans. A. Hofstadter. New York: Harper \& Row, 1971.

HENARE, A.; HOLBRAAD, M.; WASTELL, S. (Ed.). Thinking through things. London: Routledge, 2007.

INGOLD, T. Earth, sky, wind and weather. Journal of the Royal Anthropological Institute (N.S.), p. S19-S38, 2007a.

INGOLD, T. Lines: a brief history. London: Routledge, 2007b.

INGOLD, T. Materials against materiality. Archaeological Dialogues, v. 14, n. 1, p. 1-16, 2007c.

INGOLD, T. When ANT meets SPIDER; social theory for arthropods. In: KNAPPETT, C.; MALAFOURIS, L. (Ed.). Material agency: towards a nonanthropocentric approach. New York: Springer, 2008. p. 209-215.

INGOLD, T.; HALLAM, E. Creativity and cultural improvisation: an introduction. In: HALLAM, E.; INGOLD, T. (Ed.). Creativity and cultural improvisation. Oxford: Berg, 2007. p. 1-24.

KLEE, P. Notebooks, volume 1: the thinking eye. Ed. J. Spiller. London: Lund Humphries, 1961.

KLEE, P. Noteboooks, volume 2: the nature of nature. Trans. H. Norden. Ed. J. Spiller. London: Lund Humphries, 1973.

KNAPPETT, C. Thinking through material culture. Philadelphia: University of Pennsylvania Press, 2005.

LATOUR, B. On recalling ANT. In: LAW, J.; HASSARD, J. (Ed.). Actor network theory and after. Oxford: Blackwell, 1999. p. 15-25. 
LATOUR, B. Reassembling the social. Oxford: Oxford University Press, 2005.

LEFEBVRE, H. The production of space. Trans. D. Nicholson-Smith. Oxford: Blackwell, 1991.

MALAFOURIS, L.; KNAPPETT, C. Material agency. Berlin: Springer, 2008.

MILLER, D. Why some things matter. In: MILLER, D. (Ed.). Material cultures. London: UCL Press, 1998. p. 3-21.

MILLER, D. (Ed.). Materiality. Durham: Duke University Press, 2005.

OLSEN, B. Material culture after text: re-membering things. Norwegian Archaeological Review, v. 36, n. 2, p. 87-104, 2003.

PALLASMAA, J. The eyes of the skin. London: Academy Editions, 1996.

POLLARD, J. The art of decay and the transformation of substance. In: RENFREW, C.; GOSDEN, C.; DEMARRAIS, E. (Ed.). Substance, memory, display. Cambridge: McDonald Institute for Archaeological Research, 2004. p. 47-62.

RAYNER, A. D. M. Degrees of freedom. London: Imperial College Press, 1997. SIZA, A. Architecture writings. Ed. A. Angelillo. Milan: Skira Editore, 1997. TILLEY, C. The materiality of stone. Oxford: Berg, 2004.

TILLEY, C. Materiality in materials. Archaeological Dialogues, v. 14, n. 1, p. 16-20, 2007. 